\title{
ENERGY EFFICIENCY IN INDUSTRY 4.0: ASSESSING THE POTENTIAL OF INDUSTRY 4.0 TO ACHIEVE 2030 DECARBONISATION TARGETS
}

\author{
SIMONE MAGGIORE, ANNA REALINI, CLAUDIO ZAGANO, FRANCESCA BAZZOCCHI, \\ ELENA GOBBI \& MARCO BORGARELLO \\ Ricerca sul Sistema Energetico - RSE S.p.A., Italy.
}

\begin{abstract}
The energy transition for the industrial sector is not limited to a reduction in energy consumption: the real issue is to combine sustainability with growth, by mixing the two ingredients (the rational energy use and the industrial growth) which are not always compatible. The National Energy and Climate Plan (NECP) and the New Green Deal policies in Italy have the goal to promote an economic development as well as the environment sustainability and social inclusion. $\operatorname{RSE}^{1}$ has investigated the role of the national incentive plan 'Impresa 4.0' in Italy (currently 'Transizione 4.0', equivalent to 'Industry 4.0') as a measure to promote the energy transition, analysing whether and how is it possible to combine economic development with energy efficiency. Originally, it was developed to increase the competitiveness of industrial sector, but, progressively, it was also used to promote energy efficiency and sustainability. A survey was carried out by RSE on about 300 companies that implemented innovation and digitalisation interventions, monitoring the effects and impacts that the ' 4.0 choice' has determined on energy consumption, on their environmental externalities and, in general, on other costs. Moreover, some case studies were collected, together with a database of 'Impresa 4.0' application, which supported technical and economic evaluations. The impact of these measures on energy performance of the companies was estimated from the analysis of actual projects and from interviews and discussions with the operators. In this paper, the results of the survey are presented and the outcomes are analysed in comparison with the Italian manufacturing sector performance, in order to establish the potential of 'Impresa 4.0' policies in supporting the decarbonisation process and reaching 2030 environmental targets.

Keywords: decarbonisation, energy efficiency, environmental externalities, Industry 4.0.
\end{abstract}

\section{INTRODUCTION}

The technological transformation, which is identified with the term 'Industry 4.0', is substantially guided by the intertwining of the processes of technological innovation and digitalisation, to optimise and make production processes more flexible and, consequently, obtain advantages in terms of competitiveness on the market.

In this context, one of the key factors is the energy consumption which must be optimised to achieve production objectives in the least expensive and most profitable way, balancing the several variables involved in production processes. This approach, supported by digital opportunities, allows, in many cases, to reduce the energy intensity of production processes, in the logic and spirit at the basis of the energy transition. To have a deeper perception of the interweaving of innovation/digitalisation and energy efficiency, RSE has planned an in-depth study, making use of the experience and the suggestions of various stakeholders in the sector [1].

The Industry 4.0 incentive plan in Italy was initially developed to increase the competitiveness of the industrial sector; but, progressively, it was reshaped to promote and direct this progress at energy efficiency and sustainability, in order to become a measure to promote the

\footnotetext{
1 RSE stands for 'Ricerca sul Sistema Energetico' (http://www.rse-web.it/home.page), a publicly owned company whose mission is to carry out publicly funded national and international programmes in the fields of electrical power, energy and the environment.
} 
energy transition. A new approach to 'efficiency' was created: not only 'energy efficiency' and 'energy saving' but also 'overall system efficiency'. Which means further increase in energy savings and an 'optimisation' of production, environmental constraints, water and soil consumption, and finally also personnel safety.

\section{THE SURVEY}

\subsection{Literature review and previous works}

Industry 4.0 represents a great opportunity for companies but, at the same time, it is big challenge which requires new skills and visions to fully obtain its benefits.

It is not surprising, therefore, that Industry 4.0 and the related innovations and potential competitive advantages for companies have undergone and are currently undergoing a profound investigation by many actors, both within the companies and external to them, under the pressure of national government, which are eager to know the results of their policies and put in place the requires corrections in order to strengthen the support mechanisms.

Many of the existing surveys, however, fail to provide quantitative data, in particular on the relation between energy efficiency and Industry 4.0-related technologies and investments. For example, in [2], the authors have investigated how much the Italian manufacturing companies are ready to be concretely involved in the Industry 4.0 journey, focusing on analysing the knowledge and adoption levels of specific technologies, and pointing out the main benefits and obstacles, but no quantitative data are provided. In [3], the authors provide a comprehensive review of Industry 4.0-associated topics such as intelligent manufacturing, Internet of Things (IoT)-enabled manufacturing and cloud manufacturing, but a quantification on the benefits of these items on the companies' business and energy performances cannot be found. [4] shows how Industry 4.0 can be a game changer, helping companies to control their energy spending, allow them to use equipment more efficiently and provide greater flexibility in manufacturing, but, once again, a quantification of such benefits is lacking. [5] states that Industry 4.0 will enable companies not only to organise their production process more efficiently but also to manufacture customised products within the framework of and at the same cost as automated manufacturing; however, at least an estimation of the amount of energy efficiency improvement, and consequent energy and costs savings, is missing. Finally, in the 'Digital Energy Efficiency Report 2020' [6] made by the Energy Strategy Group from Politecnico di Milano, one of the most influential institutions in Italy, quantitative data about the impact of Industry 4.0 technologies in terms of improved energy efficiency in companies, is not available.

Quantitative data would be very helpful to concretely grasp the effect and consequences of Industry 4.0 interventions of the companies' daily activities and business.

\subsection{Survey design}

As already said before, most of the existing surveys about Industry 4.0 are qualitative; to fill this gap, RSE has planned a survey with the goal to provide quantitative results, using a bottom-up approach starting with companies' experience in the field, thus allowing to draw conclusions on the effectiveness of the national incentive plan 'Impresa 4.0' in Italy using quantitative data provided by companies which actually implemented real intervention in their daily activities. 
Thanks to the collaboration with large- and medium-sized companies, with trade associations such as Confindustria, with research institutions such as Cesisp, which have strong links with the University of Milano-Bicocca in Milan, and with service providers such as FIRE, which also manages the register of energy managers in Italy, RSE was granted access to a network of companies which are usually not accessible without having the previously mentioned 'ambassadors' to gain companies' managers' trust and consequent willingness to share sensitive data about investment within their companies.

This monitoring activity has involved the companies that have carried out energy efficiency interventions and/or have made use of the incentives provided for by the Industry 4.0 incentive plan (and subsequent ones) established by the Italian government.

Through the implemented survey, RSE aimed to analyse whether and how it is possible to combine digitalisation and economic development with energy efficiency. Therefore, the respondents were asked to provide information and data related to the impact of the adoption of technologies supported by the Industry 4.0 incentive plan. The collected information included the types of adopted technologies, electricity, heat and water consumption data before and after interventions and related savings. The reduction/increase in waste production and labour costs was also investigated. The impacts were calculated in terms of energy costs and overall production efficiency of companies. It important to point out that, in order to distil only the benefits coming from Industry 4.0 investments, all other factors (such as production increase/decrease, ...) have been taken into account.

The reasons and barriers underlying the choice to use the Industry 4.0 incentive plan have been investigated too. The answers to the survey were collected through a Computer-Assisted Web Interview (CAWI) and processed in an anonymous way, as most of them were sensitive data; this has allowed RSE to collect an important series of in-field experiences by those stakeholders operating the industrial sector.

\subsection{Characterisation of the sample of companies}

The survey was carried out on a sample of companies belonging to the manufacturing sector in Italy, chosen to be as heterogeneous as possible, in order to obtain representative data of industries of different sectors and size. The analysis focused mainly on manufacturing companies as such sector made more use of the Industry 4.0 incentive plan, as also emerges from the report of the Centro Studi Confindustria 'Un cambio di paradigma per l'industria italiana: gli scenari di politica economica' [7] which reports the data, referring to 2017, of the policies for economic growth, including the Industry 4.0 incentive plan. The companies involved in the survey are in the North (65\%), in the Centre (24\%) and in the South (11\%), as shown in Fig. 1.

As shown in Fig. 2, the composition of the sample is characterised for $40 \%$ by medium/ large companies, with a total revenue larger than 100 million euros and more than 250 employees: therefore, these companies are structurally prepared, for budget availability, size of plants and size of consumption, to perform interventions affecting energy saving and the production process. The remaining part is composed of companies with more than 50 employees (31\%) and with less than 50 employees and a turnover of less than 10 million euros (29\%).

The companies involved in the survey are, on average, more energy intensive than the national average: $13 \%$ of them, in fact, declare a ratio between energy costs and turnover comprised in the $10-15 \%$ range, while, the entire national manufacturing sector is 


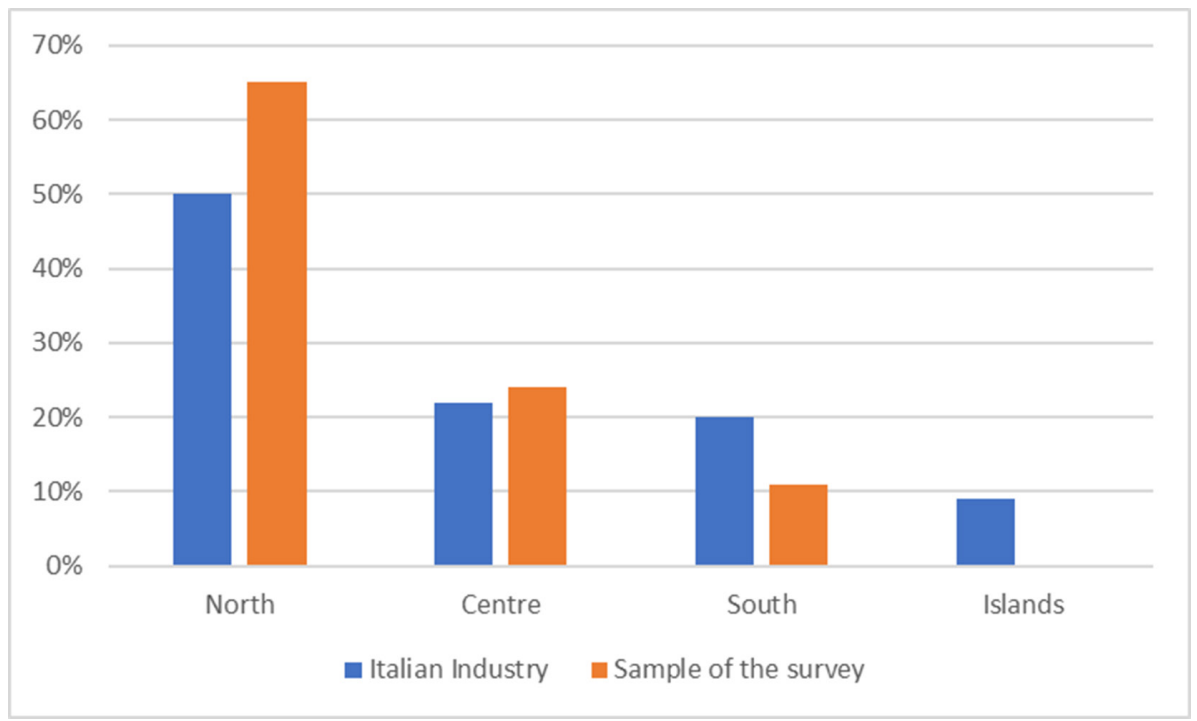

Figure 1: Territorial distribution of companies involved in the survey in comparison to the Italian companies' distribution [1].

(a)

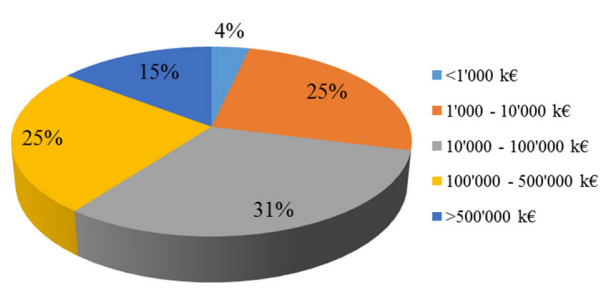

(b)

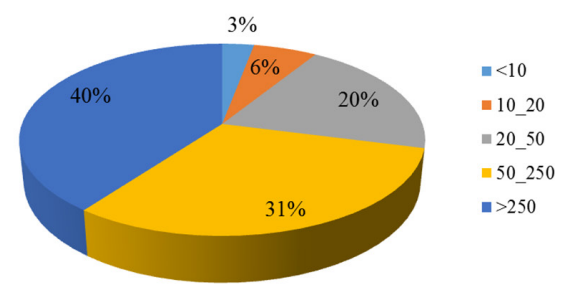

Figure 2: Distribution of companies involved in the survey based on the value of total annual revenues (a) and on the number of employees (b).

considered, this figure goes down to $6 \%$ [8]; on the other hand, $40 \%$ of the companies involved in the survey can be found in the $0-5 \%$ range, while the same figure for the entire national manufacturing sector is $58 \%$ [8].

In terms of product coverage, as shown in Table 1 (breakdown by NACE sector classification), $23 \%$ of companies belong to the metallurgy sector, that, also according to the Confindustria report [7], is the most active in investing in digital technologies. The following sectors are the processing of non-metallic minerals, in particular glass, ceramic and cement $(15 \%)$, and the chemical sector $(11 \%)$.

\section{RESULTS OF THE SURVEY}

\subsection{Energy efficiency interventions}

The results of the survey show that $96 \%$ of the companies carried out at least one energy efficiency intervention in the last 10 years. Among these, the most widespread intervention 
Table 1: Distribution of companies involved in the survey based on NACE sector classification.

\begin{tabular}{lll}
\hline NACE & Sector & Percentage \\
\hline $\mathbf{2 4}$ & Manufacture of basic metals & $23.1 \%$ \\
$\mathbf{2 3}$ & Manufacture of other non-metallic mineral products & $15.4 \%$ \\
$\mathbf{2 0}$ & Manufacture of chemicals and chemical products & $11.3 \%$ \\
& Non-manufacture & $10.5 \%$ \\
$\mathbf{2 2}$ & Manufacture of rubber and plastic products & $6.9 \%$ \\
$\mathbf{2 5}$ & Manufacture of fabricated metal products, except machinery and & $6.5 \%$ \\
& equipment & \\
$\mathbf{1 7}$ & Manufacture of paper and paper products & $5.3 \%$ \\
$\mathbf{2 6}$ & Manufacture of computer, electronic and optical products & $4.0 \%$ \\
$\mathbf{2 8}$ & Manufacture of machinery and equipment n.e.c. & $4.0 \%$ \\
$\mathbf{2 7}$ & Manufacture of electrical equipment & $3.6 \%$ \\
$\mathbf{1 8}$ & Printing and reproduction of recorded media & $2.4 \%$ \\
$\mathbf{2 9}$ & Manufacture of motor vehicles, trailers and semi-trailers & $1.6 \%$ \\
$\mathbf{1 0}$ & Manufacture of food products & $1.2 \%$ \\
$\mathbf{1 9}$ & Manufacture of coke and refined petroleum products & $1.2 \%$ \\
$\mathbf{3 1}$ & Manufacture of furniture & $1.2 \%$ \\
$\mathbf{1 1}$ & Manufacture of beverages & $0.4 \%$ \\
$\mathbf{1 3}$ & Manufacture of textiles & $0.4 \%$ \\
$\mathbf{2 1}$ & Manufacture of basic pharmaceutical products and & $0.4 \%$ \\
$\mathbf{3 0}$ & pharmaceutical preparations & \\
\hline & Manufacture of other transport equipment & $0.4 \%$ \\
\hline
\end{tabular}

concerns lighting, followed by the installation of inverters or high-efficiency electric motors and from interventions on the compressors, as shown in Fig. 3.

Overall, the interventions resulted in different levels of energy savings depending on the adopted technology. About $60 \%$ of the companies involved in the survey declares electrical and/or thermal savings in the $1-5 \%$ range, while for the remaining companies, the savings are more significant and can even exceed $10 \%$ (Fig. 4).

In $3 \%$ of the companies, a 'cross effect' occurred for certain types of interventions: such intervention aimed at reducing only electrical or thermal consumption, but it had the effect of increase the consumption of the other source, although with an overall positive energy balance. This effect often depends on the type of intervention carried out, such as in cases of installation of a system of cogeneration, which can result in an increase in the overall efficiency of the system in the face of a local increase in gas consumption.

\subsection{Industry 4.0 interventions}

The results of the survey show that $57 \%$ of the companies involved in the survey implemented interventions which are eligible for incentives under the Industry 4.0 incentive plan. This shows the interest from companies towards this type of technology and related mechanisms, considering that, with respect to the incentives for energy efficiency (active since 


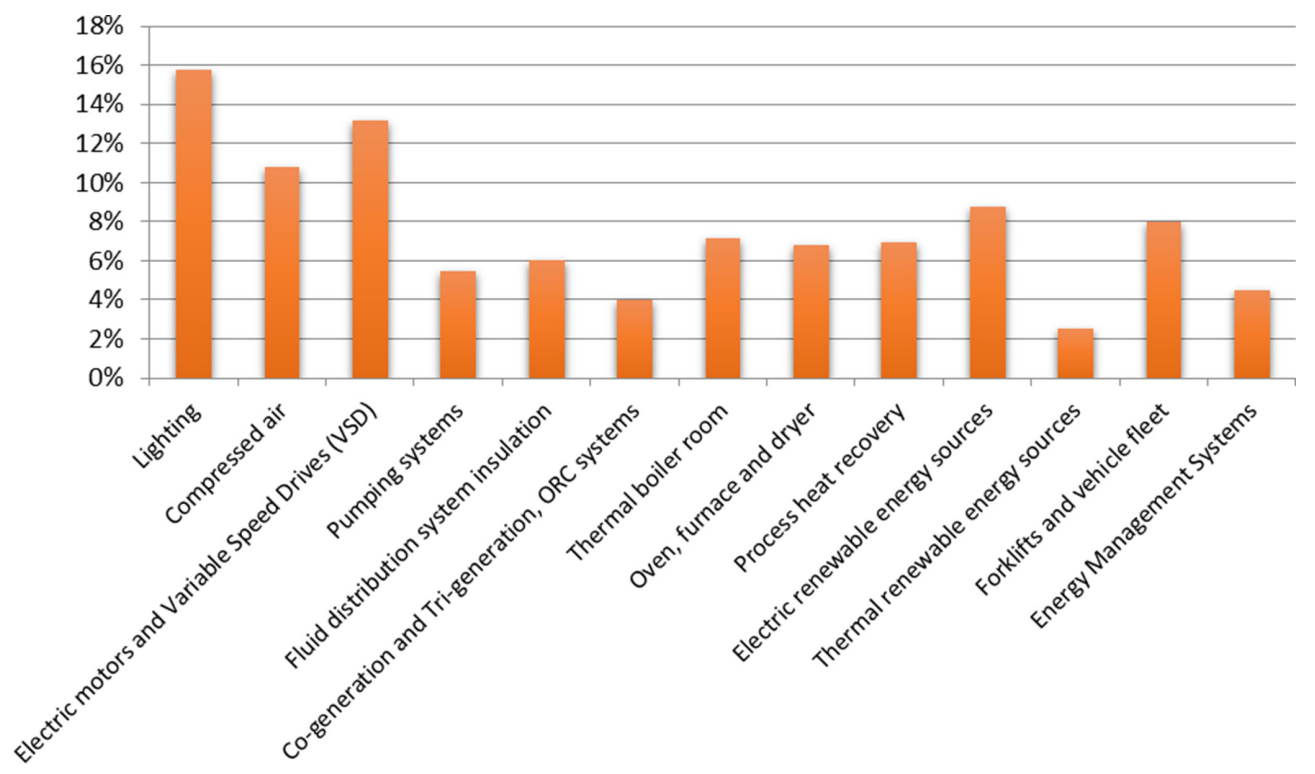

Figure 3: Distribution of energy efficiency interventions among the companies involved in the survey.

(a)

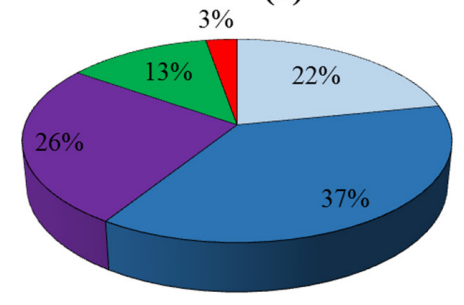

(b)

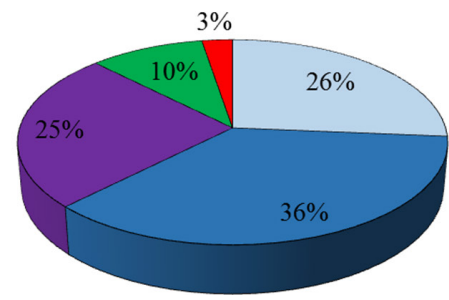

$\square$ decrease $(<1 \%)$

$\square$ decrease $(1-5 \%)$

$\square$ decrease $(5-10 \%)$

$\square$ decrease $(>10 \%)$

$\square$ increase $(<10 \%)$

Figure4: Impact of the energy efficiency interventions on the electric (a) and thermal (b) consumption for the companies involved in the survey.

2005), actions to promote Industry 4.0 measures have been introduced only 2017 . The interventions were grouped into the following categories [9]:

1. Industrial Internet of Things (IIoT)

2. Cloud Manufacturing

3. Industrial Analytics

4. Advanced HMI

5. Advanced Automation

6. Additive Manufacturing

7. Augmented Reality 
8. Advanced Manufacturing Solutions

9. Cybersecurity

10. Horizontal/Vertical Integration

11. Simulation

As shown in Fig. 5, the most applied type of intervention is 'Advanced Automation' (18\%), followed by 'Cybersecurity' (13\%) and 'Industrial IoT' (11\%) interventions.

In order to analyse the impact of Industry 4.0 interventions, RSE has analysed the energy consumption before and after the interventions, thus setting a baseline consumption upon which a reduction/increase could be asserted. Moreover, as already said before, the energy savings were cleaned from other factors affecting the processes independently of Industry 4.0 interventions, such as production increase/decrease or increase in energy costs.

As regards the impact of Industry 4.0 interventions electricity consumption, it results that in more than half of the involved companies, energy savings were measured and such savings are in the range $1-20 \%$ for about $50 \%$ of the companies. On the contrary, electricity consumption increased as a result of the implementation of Industry 4.0 technologies for $11 \%$ of the companies, even if such an increase is less than 5\% (Fig. 6).

The reason lies in the larger demand for electricity of some control or automation systems, but also from the different management of the system, that can lead to maximise production at the expenses of energy efficiency.

The impact of Industry 4.0 interventions on thermal consumption is less than the one on electricity consumption: in fact, only $38 \%$ of the companies experienced a decrease in thermal consumption; on the other hand, $2 \%$ of the companies reported an increase in thermal consumption, attributable, however, to particular cases, relating to specific types of production (Fig. 7).

It is important to highlight that, in this case, energy consumption decrease is a secondary effect and not the reason which led companies to implement a particular Industry 4.0 technology.

In terms of reduction of water and waste consumption, the impact of Industry 4.0 interventions is lower, compared to that of electrical and thermal consumption: in fact, it occurs only in $17 \%$ and $21 \%$ of companies as regards, respectively, water and waste consumption.

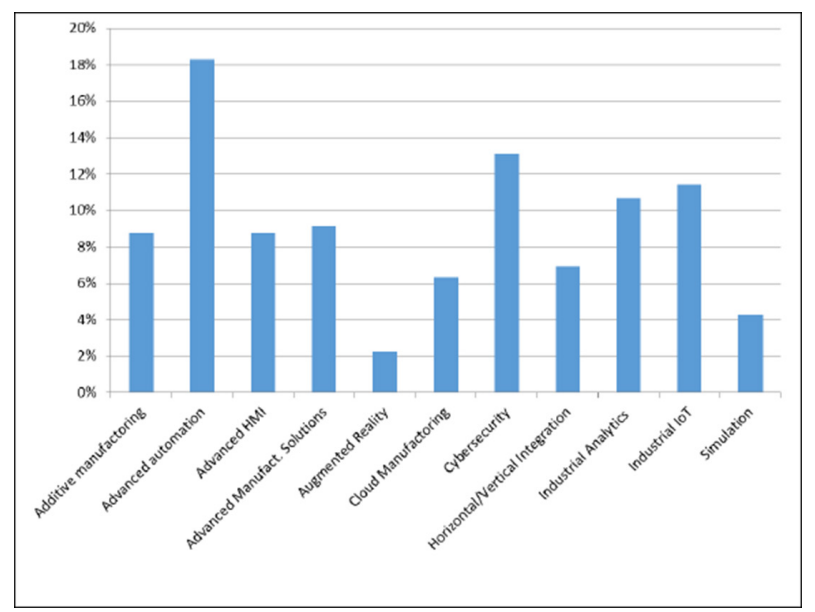

Figure 5: Share of implementation of interventions which are eligible for incentives under the Industry 4.0 incentive plan for the companies involved in the survey. 


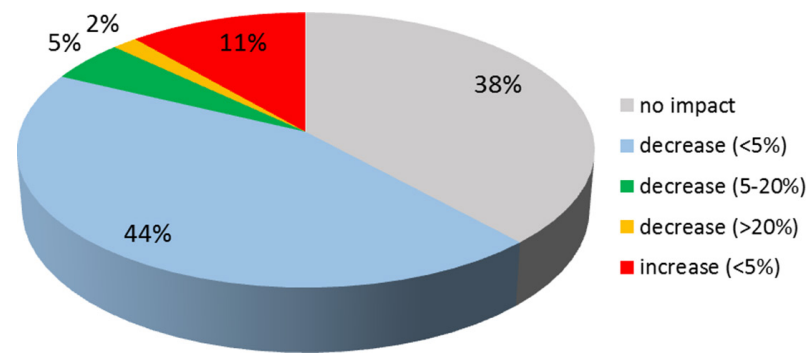

Figure 6: Impact of the Industry 4.0 interventions on the electric consumption for the companies involved in the survey.

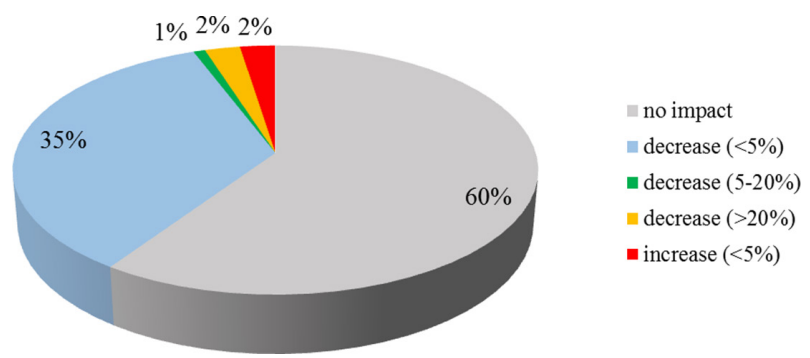

Figure 7: Impact of the Industry 4.0 interventions on the thermal consumption for the companies involved in the survey.

The effect on labour costs, on the other hand, appears to be more significant. In $50 \%$ of cases, in fact, digitalisation and automation technologies also led to a reduction in costs of the personnel involved. Eight percent of the companies have, instead, experienced an increase in labour costs, probably attributable to the cost of specific training for the use or the maintenance of the installed technologies (Fig. 8).

Figure 9 shows the average electrical and thermal energy savings for the different Industry 4.0 interventions. The average energy savings can be found in the $0-3 \%$ range and are larger in those interventions which provide an organic and integrated vision of the whole production process, such as the 'Cloud Manufacturing' and the exchange of integrated information. Considerable savings can also be generated by those interventions involving a human-machine interface, to convey and organise the information regarding components and process data. It was also noted that, for some interventions, the percentages of energy savings are unbalanced towards thermal ones, i.e. the use of heat for production processes. The capability to interconnect the different phases of the process and the dynamic control of the system components can, in fact, facilitate a more optimised use of thermal vectors, both cold and heat. One of the main reasons for the energy savings achievable by digitisation is the reduction of manufacturing defects. In fact, digitisation allows for more efficient control of processes, resulting in the reduction of defective products. Each avoided defective product translates, in turn, into lower energy consumption and lower consumption of raw materials with consequent economic advantage. 
(a)

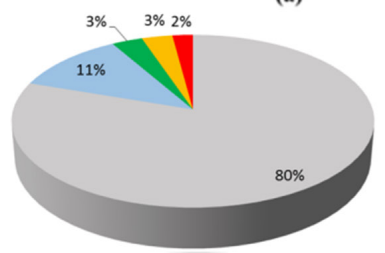

(b)

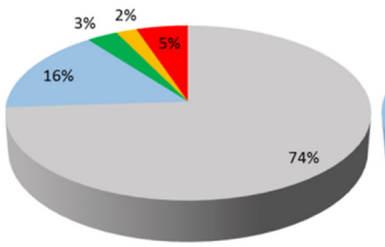

(c)

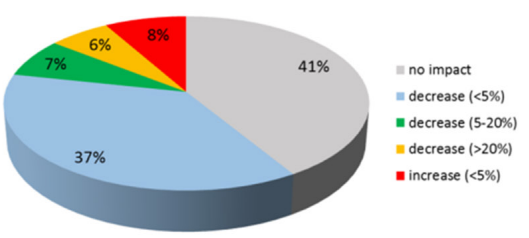

Figure 8: Impact of the Industry 4.0 interventions on the water consumption (a), waste consumption (b) and labour cost (c) for the companies involved in the survey.

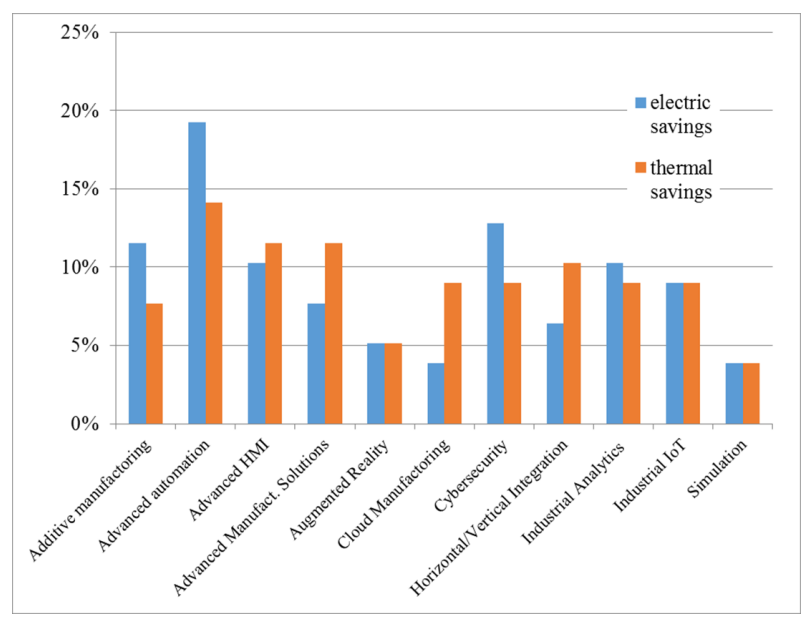

Figure 9: Average electrical and thermal energy savings for the different Industry 4.0 interventions implemented by the companies involved in the survey.

\section{ESTIMATION OF POTENTIAL ENERGY SAVINGS FOR THE DIFFERENT SECTORS}

Starting from the cross among the data on the types of companies, the implemented Industry 4.0 interventions and the related electricity and thermal savings, electrical and thermal energy savings, with respect to baseline consumption, were estimated, for those NACE sectors with a statistical significance, in order to be able to generalise the answers (Table 2).

Energy savings are in the 0-3\% range: this is an estimate based on data from a sample of companies, but, based on RSE experience and knowledge of the industrial sector in Italy, it appears that these values represent a semi-quantitative indication of the savings achievable by Industry 4.0 measures.

\section{CONCLUSIONS}

The main conclusion of this analysis is that Industry 4.0 incentive plan, even if it does not have the achievement of energy efficiency in companies among its objectives (in fact, many of the companies did not plan Industry 4.0 intervention to increase energy efficiency in their 
Table 2: Estimation of potential electrical and thermal energy savings with respect to baseline consumption for some NACE sectors.

\begin{tabular}{|c|c|c|c|}
\hline NACE & Sector & $\begin{array}{l}\text { Potential } \\
\text { electric } \\
\text { energy } \\
\text { savings }\end{array}$ & $\begin{array}{l}\text { Potential } \\
\text { thermal } \\
\text { energy } \\
\text { savings }\end{array}$ \\
\hline 17 & Manufacture of paper and paper products & \multirow{2}{*}{$0.2 \%$} & \multirow{2}{*}{$0.2 \%$} \\
\hline 18 & Printing and reproduction of recorded media & & \\
\hline 20 & Manufacture of chemicals and chemical products & $0.5 \%$ & $0.3 \%$ \\
\hline 21 & \multicolumn{2}{|l|}{$\begin{array}{l}\text { Manufacture of basic pharmaceutical products and phar- } \\
\text { maceutical preparations }\end{array}$} & \\
\hline 22 & Manufacture of rubber and plastic products & $2.2 \%$ & $1.3 \%$ \\
\hline 23 & Manufacture of other non-metallic mineral products & $2.6 \%$ & $2.2 \%$ \\
\hline 24 & Manufacture of basic metals & $2.9 \%$ & $2.2 \%$ \\
\hline 25 & $\begin{array}{l}\text { Manufacture of fabricated metal products, except ma- } \\
\text { chinery and equipment }\end{array}$ & $3.1 \%$ & $0.3 \%$ \\
\hline 26 & $\begin{array}{l}\text { Manufacture of computer, electronic and optical prod- } \\
\text { ucts }\end{array}$ & 0 & $0.3 \%$ \\
\hline 27 & Manufacture of electrical equipment & & \\
\hline 28 & Manufacture of machinery and equipment n.e.c. & $1.5 \%$ & 0 \\
\hline
\end{tabular}

companies but to improve their digitalisation), was able to improve it in many of the companies who benefitted from such a support scheme.

In fact, the constant monitoring and control of machinery equipped with technologies allowing process optimisations were able to improve energy efficiency in companies, leading to a reduction not only in electricity and thermal consumptions but also, in some cases, in water and waste consumptions and in labour costs.

This digitalisation and related benefits stemming from Industry 4.0 intervention will certainly make a significant contribution in the EU decarbonisation path [10] and will be very useful to the achievement of the EU objectives for 2030. In order for the policy makers to develop different policies that aim at the decarbonisation goals, the Industry 4.0 tool might be an effective ally, even if not designed on-purpose to address Energy Efficiency such as other incentive mechanisms (e.g. White Certificates, ...) specifically designed to support energy efficiency in the industrial sector.

\section{ACKNOWLEDGEMENTS}

This work was financed by the Research Fund for the Italian Electrical System in compliance with the Decree of Minister of Economic Development on 16 April 2018.

\section{REFERENCES}

[1] Bazzocchi, F., Borgarello, M., Gobbi, E., Maggiore, S., Realini, A. \& Zagano, C., L'industria efficiente: Le opportunità delle imprese nella transizione energetica, editrice Alkes, ISBN 978-88-943145-2-6, 2020. 
[2] Zheng, T., Ardolino, M., Bacchetti, A., Perona, M. \& Zanardini, M., The impacts of Industry 4.0: a descriptive survey in the Italian manufacturing sector. Journal of Manufacturing Technology Management, ISSN: 1741-038X, Dec. 2019.

[3] Zhong, R.Y., Xu, X., Klotz, E. \& Newman, S.T., Intelligent Manufacturing in the Context of Industry 4.0: A Review. Engineering, 3(5), pp. 616-630, 2017. https://doi. org/10.1016/j.eng.2017.05.015

[4] Schenkel, R., Industrie 4.0 Opportunity Discovery Workshop; Online, https://atos.net/ wp-content/uploads/2017/04/atos-industry-4-0-opportunity-discovery-workshop-brochure.pdf. Accessed on: 21 Jun 2021.

[5] Schröder, C., The Challenges of Industry 4.0 for Small and Medium-sized Enterprises, Division for Economic and Social Policy, 2016.

[6] Energy Strategy Group, Digital Energy Efficiency Report 2020; Online, https://www. energystrategy.it/osservatorio-di-ricerca/digital-energy-efficiency/?2020. Accesses on: 21 Jun 2021.

[7] Nota dal Centro Studi Confindustria; Centro Studi Confindustria, Numero 5/20 - 12 agosto 2020; Online, https://www.confindustria.it/wcm/connect/5a7c8fdc-2a0d-4d5a-8f9f9b59e9824a86/Nota+CSC_Industria_4.0_120820_Confindustria.pdf?MOD=AJPERES\&CACH EID=ROOTWORKSPACE-5a7c8fdc-2a0d-4d5a-8f9f-9b59e9824a86-nfxB5Ad. Accessed on: 25 Mar. 2021.

[8] Faiella, I. \& Mistretta, A., Spesa energetica e competitività delle imprese italiane, Banca d'Italia, Numero 214, p. 22, Mar. 2014.

[9] Zagano, C., Sistemi di gestione dell'energia. Impresa 4.0 ed efficienza energetica: a che punto siamo?, Ricerca di Sistema, RSE n 20000096, Milano, 2019.

[10] FINAL REPORT of the High-Level Panel of the European Decarbonisation Pathways Initiative; Online, https://ec.europa.eu/info/sites/default/files/research_and_innovation/ research_by_area/documents/ec_rtd_decarbonisation-report_112018.pdf. Accessed on: 21 Jun. 2021. 